\title{
М.О. Тяпкин
}

\section{ЛЬГОТНЫЕ ОТПУСКИ ДРЕВЕСИНЫ НАСЕЛЕНИЮ КАК ЭЛЕМЕНТ СИСТЕМЫ ОХРАНЫ ЛЕСОВ ЮГА ЗАПАДНОЙ СИБИРИ В ПЕРВОЙ ЧЕТВЕРТИ ХХ в.}

\begin{abstract}
Рассматривается система льготных и бесплатных отпусков леса, существовавшая на юге Западной Сибири и являвшаяся одним из способов предупреждения несанкционированного лесопользования и лесных пожаров. Правила бесплатного и льготного снабжения населения древесиной из государственных и ведомственных лесных дач претерпевали существенные изменения в зависимости от политической обстановки в регионе и принципов лесной политики, закрепленных в законодательстве. Показана эволюция подходов к организации льготного снабжения населения древесиной в зависимости от смены политического режима.

Ключевые слова: лесопользование; лесоохрана; льготный отпуск леса; лесная такса; лесорубочный билет; самовольная рубка леса.
\end{abstract}

Действующее законодательство предусматривает возможность получения каждым гражданином Российской Федерации определенного объема лесоматериалов на собственные нужды, в том числе валежника на дрова. Однако сама процедура получения разрешения на заготовку валежного леса очень длительна (от 90 до 120 дней) и обставлена многочисленными бюрократическими препонами. В июне 2016 г. депутаты Алтайского краевого законодательного собрания разработали и направили в Государственную думу законопроект, упрощающий процедуру получения населением валежного леса. Законопроект предусматривает возможность для местного населения бесплатно заготавливать валежник на дрова, что позволит очистить лесные дачи от сотен тысяч кубометров мертвой древесины, представляющей опасность в пожарном отношении и являющейся благоприятной средой для размножения вредителей леса. Отечественная система бесплатных и льготных отпусков леса населению, существующая в современном виде, имеет достаточно долгую историю, что необходимо учитывать в правотворческой и правоприменительной деятельности.

Лесопользование в Сибири носило вольный, практически ничем не ограниченный характер вплоть до конца XIX в., т.е. времени резкого возрастания эксплуатационной нагрузки на леса региона. По сложившейся традиции местное крестьянское население до завершения землеустройства имело право на бесплатное получение строевого и дровяного леса на собственные нужды из казенных и ведомственных лесных дач. Это право могло быть реализовано при условии участия в тушении лесных пожаров и работах по опалке лесных дач. Активизация хозяйственной деятельности казенного лесного ведомства и Кабинета его императорского величества (далее - Кабинет) и увеличение темпов переселенческого движения на юг Западной Сибири привели к тому, что в отдельных уездах появляется дефицит лесных материалов, грозивший перерасти в более опасное явление - так называемый лесной голод. В этих условиях власть вынужденно брала на себя обязательства по обеспечению населения необходимой древесиной для снижения социальной напряженности в деревне.

Реализация этой политики шла несколькими путями. Во-первых, за счет выделения крестьянам лесных наделов в процессе проведения землеустройства. Однако отвод лесных наделов был крайне неравномерен, в значительной степени зависел от местных условий и нежелания лесовладельца выделять населению участки ценного строевого леса, в результате чего «в некоторых районах, особенно в лесостепной зоне, крестьяне фактически оставались без лесных наделов» [1. С. 285].

Во-вторых, казна и Кабинет пытались решать вопрос снабжения местного населения древесиной одновременно с развитием собственной лесохозяйственной деятельности за счет организации лесных складов для продажи древесины. Однако высокая стоимость лесоматериалов, удаленность лесных складов от населенных пунктов, сложности и бюрократические проволочки в оформлении лесорубочных документов в сочетании с невозможностью или нежеланием основной части населения приобретать лес у казны и Кабинета значительно затруднили успешную реализацию данного направления.

Третьим способом удовлетворения потребности крестьян в лесоматериалах являлась система бесплатного и льготного отпуска, распространявшаяся как на все население, так и на отдельные его категории. В первом случае речь шла преимущественно о санитарных очистках лесных дач от мусора (порубочных остатков, горелого и валежного леса), который отпускался по сниженной цене или, при невозможности продажи, бесплатно по упрощенной процедуре. Крестьяне обязывались провести очистку лесной дачи от всего валежника, отвечая «круговой порукой за срубку и повреждение леса стоячего и за всякие нарушения Лесного устава» [2. С. 117].

Очистка лесных дач и гарей от мертвого леса рассматривалась как одна из важнейших противопожарных мер. На съезде земельно-лесных чинов Алтайского округа в 1910 г. было решено, что «все старания со стороны администрации должны быть направлены к тому, чтобы в лесных дачах было как можно меньше валежа» [3. С. 163]. Безусловно, система была далека от совершенства. Зачастую крестьяне выбирали из гарей самый лучший лес, а сильно поврежденные деревья или находившиеся в труднодоступных местах оставались. Желание дешево получить относительно качественный лес толкало крестьян на умышленные поджоги близлежащих дач. Для борьбы с этим явлением существовал единственный проверенный спо- 
соб: свежегорелый лес отпускался по полной таксе, а снижение таксовых цен допускалось только в старых гарях и в соответствии со степенью утери лесом технических его свойств.

В годы обострения социальных противоречий и массовых выступлений крестьян возрастали объемы бесплатных и льготных отпусков с целью «умиротворения» деревни, в первую очередь семьям нижних воинских чинов, возвращавшихся с фронта в 19051906 гг. В казенных лесах самые большие объемы бесплатных и льготных отпусков были зафиксированы в 1906 и 1907 гг., стоимость которых существенно превышала показатели за предыдущие и последующие годы [4. С. 144]. Во время Первой мировой войны в казенных и кабинетских лесничествах наблюдалась тенденция увеличения объемов льготных и бесплатных отпусков дровяного леса населению с одновременным сокращением доходов от реализации древесины. Упрощалась процедура продажи крестьянам казенного леса без торгов и с отсрочкой платежа. Лесничие могли собственной властью наполовину снижать таксовую стоимость лесных материалов.

Льготное снабжение местного населения древесиной практиковалось местной администрацией даже в ущерб провозглашенному курсу на повышение доходности казенного и кабинетского хозяйства. Сторонником увеличения социальной нагрузки на лесную отрасль стал начальник Алтайского округа В.П. Михайлов [5. С. 78-83; 6. С. 91-98]. Кабинетская администрация долгое время не хотела признавать, что остроту лесного вопроса, особенно после революционных событий февраля 1917 г., мог снизить только компромисс с населением в решении вопросов землеи лесопользования. Основным способом снижения нарастающей социальной напряженности являлось увеличение объемов бесплатных отпусков леса, в первую очередь семьям призванных в армию солдат. Весной 1917 г. было решено бесплатно отпускать солдаткам 2 куб. м в год дровяного леса, не допуская назначения отдаленных делянок, и проводить рубки даже в тех местах, где они были запрещены по лесозащитным показателям.

В декабре 1917 г. на первой сессии постоянного лесохозяйственного совещания при Управлении Алтайского округа с участием представителей общественных организаций был рассмотрен вопрос льготных и бесплатных отпусков валежного, сухостойного и сырорастущего леса и принято решение, оформленное в виде циркулярного предписания лесничим [7. Л. 174-175]. Речь шла о системе бесплатных и льготных отпусков беднейшему населению Алтайской губернии, поскольку порядок отпуска на нужды семей призванных в армию солдат оставался без изменений.

Право на бесплатное получение валежника на собственные потребности имели семьи солдат, призванных в армию, а также беднейшее население. Для устранения разночтений циркуляр определял, что валежником может считаться всякий лежащий лес, в том числе порубочные остатки, за исключением срубленного и подготовленного к вывозу, свежего бурелома и растущих деревьев, поврежденных огнем. Од- новременно были выработаны критерии, по которым сельские комитеты могли признать семью малоимущей или «беднейшей». Попасть в эту категорию могли те, кто имел в семье не более двух лошадей и одной коровы и не получал доходов от торговли или промыслов. Однако преимущественное право получения валежа имели семьи военнослужащих. После утверждения списков льготников волостным земельным комитетом лесничий определял район, время и порядок проведения заготовок. Выборка леса осуществлялась по лесорубочному билету, чтобы не допускать абсолютно бесконтрольного пользования лесными материалами. Учитывая сложную обстановку, лесничие могли самостоятельно определять необходимость освидетельствования заготовок.

Кроме того, беднейшему населению, при отсутствии собственных лесных наделов, мог отпускаться деловой лес по льготной цене со скидкой 50\% [8. Л. 16 об.]. Нормы льготных отпусков были установлены для 52 лесничеств, еще 5 лесничеств (Бахматовское, Бийское, Коробейниковское, Колыванское, Мормышанское) были исключены из этого списка «в виду крайней истощенности лесных дач».

В черневых (таежных) дачах бесплатный отпуск был неограничен и распространялся на все население по согласованию между лесничими и земельными комитетами. В черневых дачах к валежнику относились также пни и «сломки без живых сучьев». Пользование осуществлялось по билету, что давало возможность привлекать лесозаготовителей к ответственности за поджоги леса вследствие неосторожного обращения с огнем, самовольные порубки и прочие нарушения законодательства, на общих основаниях.

Временное установление советской власти в Западной Сибири весной 1918 г. привело к пересмотру системы лесопользования и лесоохраны. В конце апреля 1918 г. Лесной подотдел Земельного отдела Алтайского губернского Совета крестьянских и рабочих депутатов подготовил несколько циркуляров, устанавливавших новый порядок основного и побочного лесопользования и отпусков лесных материалов различным потребителям. Документы были составлены в духе политических взглядов РКП(б) на социальный характер лесопользования и созвучны тем, которые принимались в центре. Лесоотпускные таксы для железных дорог и коммерческих предприятий увеличивались в три раза, а на общественные нужды и для населения предусматривались льготы в виде понижения таксовой стоимости, а также бесплатный отпуск для нужд «отдельных, единичных, бедных домохозяев, острая нужда которых в лесных материалах и бедное состояние зафиксированы в общественном приговоре» [9. Л. 22 об.]. Право снижать стоимость леса при продаже его населению и выносить решение о бесплатной выдаче лесоматериалов получали земельно-лесные управы, тогда как до этого подобные решения мог принимать лишь начальник округа.

В течение месяца был разработан механизм определения нуждающихся в льготном или бесплатном отпуске лесных материалов. Единственным ограничением его объемов являлось условие, чтобы размер 
отпускаемой древесины не превышал годового отпуска из лесной дачи. Отдельно оговаривалось, чтобы валежник для домашних надобностей отпускался всем категориям населения бесплатно. За нецелевое использование полученного или приобретенного по льготной цене леса, в частности за его перепродажу, предусматривалось взыскание с нарушителя штрафной таксовой стоимости лесоматериалов.

Переход власти к Временному Сибирскому правительству положил начало постепенному восстановлению управленческого механизма и возврату к прежним принципам взаимоотношения населения и лесной администрации. Нововведения большевиков в сфере отпуска лесных материалов населению были оценены как «не имеющие законного основания и понижающие лесной доход» [9. Л. 47]. Все нормативные распоряжения большевиков были отменены и восстановлена система лесных отпусков, существовавшая до весны 1918 г.

В первое время лесничим была предоставлена значительная степень свободы в принятии решений, в том числе в вопросах обеспечения местного населения лесоматериалами за счет отпуска валежа, сухостоя, разработки гарей и лиственных насаждений. Необходимо было восстановить нормальный оборот рубок, сократить рубки в тех дачах, где отпуск превысил расчетную лесосеку, и восстановить прежнюю систему льготных и бесплатных лесоотпусков, регламентированную предшествующим законодательством.

Временное Сибирское правительство по вопросам оказания различной помощи солдатским семьям занимало вполне определенную позицию. Она заключалась в том, что семьям военнослужащих по призыву и мобилизации, а не добровольно, нужно оказывать помощь лишь в тех случаях, когда они «не в состоянии прокормиться собственными заработками или доходами от принадлежащего им имущества» [10. Л. 55]. К началу 1919 г. в губерниях юга Западной Сибири установилась единая система снабжения населения древесиной, базировавшаяся на циркулярах Лесного департамента, изданных еще в дореволюционный период, а также распоряжениях Министерства земледелия Временного Сибирского правительства и Правительства А.В. Колчака, принятых осенью и зимой 1918 г.

Правом бесплатного получения леса пользовались семьи солдат, находившихся в плену, пропавших без вести, получивших увечье или погибших, если им не была назначена пенсия. Причем данное право не распространялось на семьи солдат, призванных Временным Сибирским правительством. К отпуску предназначался валежник, сухостойный или поврежденный лес, т.е. неделовая древесина. Определение нуждавшихся в получении топлива происходило при непосредственном участии волостных земских управ, милиции и различных общественных организаций. Однако окончательное определение размера отпускаемого дровяного леса принадлежало исключительно лесничему. По действующему в казенном лесном управлении правилу одна семья могла получить не более 3 куб. саж. дров, т.е. норму, установленную для отопления домов лесной стражи [11. Л. 23 об.].
Помимо бесплатного отпуска существовала форма социальной субсидии в виде получения древесины на льготных основаниях. Правом на приобретение леса по сниженной таксовой стоимости обладали беженцы, а также жители сельской местности и городов, нуждавшиеся в силу ряда причин в лесоматериалах. Условия снижения таксовой стоимости определялись в зависимости от лесохозяйственных условий разных лесничеств, однако общим правилом являлось то, что окончательное решение о понижении таксы оставалось за лесничим, но при этом он не мог снизить стоимость леса более, чем наполовину.

Окончательное установление советской власти в регионе в конце 1919 г. означало распространение норм общероссийского законодательства на лесохозяйственную сферу Западной Сибири, в том числе по вопросам лесопользования, прежде всего, декретов ВЦИК «О лесах» от 27 мая 1918 г. и «Об отпуске трудовому населению леса и о пользовании в лесах» от 4 июня 1919 г. Несмотря на государственную монополию на любой вид лесоторговли, за гражданами оставалось право на лесопользование, в том числе получение строевой и дровяной древесины. Условием реализации этого права являлось обязательное участие граждан в работах по охране и восстановлению лесов. Нормы отпуска устанавливались в зависимости от местных условий.

Эти нормативные акты предусматривали отпуск леса по корневым ценам местному населению (по уравнительной норме) и по твердым ценам на нужды промышленности, нетрудовому населению, а также трудовым хозяйствам, если они получали этот лес сверх нормы отпуска. И в том и в другом случае цены рассчитывались исходя из существующей таксы, утверждаемой губернским земельным отделом, с той разницей, что корневые были в три раза меньше. Обе цены могла делиться на семь разрядов и увеличиваться и уменьшаться в зависимости от степени доступности лесосеки, удобства вывозки леса и пр. В связи с отменой колчаковских денег предусматривалась возможность приобретения леса в рассрочку.

В условиях Гражданской войны и упадка народного хозяйства рыночные отношения в лесном хозяйстве отошли на второй план, уступив место прямому снабжению потребителей необходимой древесиной. В целях реализации нормативных актов, устанавливавших право отдельных категорий населения на льготное получение древесины, губернские власти издавали временные положения и инструкции, которые определяли порядок и объемы отпусков. В частности, «Временная инструкция земотделам волостных ревкомов и лесничим», утвержденная в начале 1920 г. уполномоченным Алтайского губернского ревкома по Земотделу Н.И. Мелковым, устанавливала правило, по которому «отпуск леса производится по раскладке, утвержденной губернским Земотделом за плату по таксе с выдачей на каждое селение одного валового лесорубочного билета» [12. Л. 24]. Билеты выдавались в лесничествах, хотя с мест поступали предложения о выдаче билетов волостными земотделами, которые, однако, не были поддержаны 
как противоречащие закону и принципам ведения лесного хозяйства.

Распространение на регион нормативных актов советской власти и национализация лесных ресурсов создали у населения иллюзию того, что все бывшие казенные леса становились общенародным достоянием, право пользования которым принадлежит всем и каждому без каких-либо ограничений. В феврале 1920 г. заведующий Алтгубземотделом Банников был вынужден, в ответ на многочисленные ходатайства о бесплатном отпуске леса из «государственных лесов Республики», предписать всем временным районным лесным комиссиям и уездным лесным подотделам губернии «оповестить население, что никакие бесплатные отпуска леса вообще не допускаются» [12. Л. 85]. Право на бесплатное получение леса было оставлено за малообеспеченными семьями красноармейцев, лицами, принимавшими участие в государственных лесных работах (не менее одного месяца), а также пострадавшими от различных бедствий, контрреволюции и лишившимися трудоспособности. Списки «льготников» должны были ежемесячно направляться в уездные лесные подотделы, а далее - в губземотделы, где производились расчеты между отделами губревокомов (губисполкомов), за счет которых приобретались лесоматериалы. Отпуск леса должен был производиться в соответствии с установленным лесохозяйственным планом, а рубка - только при наличии лесорубочного билета с последующим освидетельствованием лесной стражей.

Порядок удовлетворения лесными материалами семей красноармейцев устанавливался общегосударственным законодательством и местными правилами и инструкциями. Объем льгот определялся социальным статусом семьи красноармейца. Так, семьи, относящиеся к категориям неимущих и середняков, но не имеющие других работников, кроме призванного в армию, получали древесину бесплатно; середняцкие семьи, в которых оставались другие работники - по льготной цене (половина от корневой); зажиточные должны были приобретать лес по его полной стоимости и фактически по остаточному принципу, т.е. после удовлетворения потребностей лиц первых двух категорий. Отводом лесосек по спискам нуждающихся в строевом и дровяном лесе семей занимался лесничий, а окончательная разверстка между потребителями производилась специальным районным совещанием. Заготовку нуждавшиеся в лесе осуществляли самостоятельно, поэтому и ответственность за переруб несли на общих основаниях как за самовольную порубку с составлением протокола и дальнейшим разбирательством. Лесные дачи были разорены порубками, в том числе самовольными, захламлены порубочными остатками, буреломом и ветровалом, поэтому уже летом 1920 г. был запрещен отпуск сырорастущего леса на дрова, если имелись доступные порубочные остатки, которые отпускались бесплатно.

Определение статуса семьи возлагалось на сельские и волостные власти, а окончательное формирование списков являлось прерогативой уездных земотделов. На практике волостные земельные отделы, в чьи функции входила разверстка отпускаемых материалов, с этой работой не справлялись, в результате чего складывалась ситуация, при которой лесничий занимался не только сугубо технической работой по отводу мест рубок, но и определял нормы отпуска потребителям. Под угрозой прекращения возможности осуществлять льготные и бесплатные отпуски советская власть была вынуждена на первых порах расширить полномочия лесничих, предоставив им возможность, хоть и не единолично, решать вопросы наделения лесом нуждающихся. Был запрещен отпуск леса, располагавшегося в бывших лесных крестьянских наделах и в пределах основных земельных наделов без ведома и согласия лесничего. Наиболее ценные крестьянские сосновые леса вообще исключались из оборота впредь до особого обследования. Сами же бывшие лесные крестьянские наделы, до проведения их полного обследования, поступали в ведение лесничих. Новая власть нуждалась в достоверной информации об объеме имеющихся запасов древесины.

В феврале 1920 г. решением Алтайской губернской межведомственной комиссии по оказанию помощи пострадавшим от контрреволюции была определена норма бесплатного отпуска в размере 35 хлыстов на постройку избы для семьи до 6 человек. Если семья насчитывала более 6 человек, на каждого члена семьи дополнительно отпускалось по 3 хлыста. Еще одной мерой социальной помощи было предоставление таким семьям права получать денежную компенсацию вместо леса по расценкам губземотдела [13. Л. 96]. Первыми на такую помощь могли рассчитывать бедняки, активно «выступавшие против колчаковщины и хозяйство которых до основания разрушено» [12. Л. 106]. Распоряжением Сибревкома права на бесплатное получение строевого леса были лишены те, кто мог получить при землеустройстве лесной надел «вне пределов своего проживания» [14. Л. 2]. Также лишались права на получение лесоматериалов те местные общества, которые отказывались от участия в тушении лесных пожаров.

Уборка мертвого леса из лесных дач по-прежнему являлась одной из важнейших предупредительных противопожарных мер. Крупные лесозаготовители практически никогда не убирали порубочные остатки, оставляя за собой захламленные делянки, оправдываясь отсутствием рабочих рук. Мелкие потребители в лице местного населения активно пользовались возможностью бесплатно получить отходы от лесозаготовок. В годовом отчете о состоянии лесного хозяйства Алтайской губернии за 1924-1925 гг. указывалось, что в легкодоступных лесных дачах с помощью широкого отпуска валежа от него уже избавились. Там же, где население нуждалось в лесе меньше, а также в труднодоступных местах лесные дачи оставались захламленными [15. Л. 3 об.].

На протяжении 1920-х гг. порядок лесоотпуска в РСФСР менялся неоднократно, что было продиктовано особенностями развития народного хозяйства и складыванием новой системы лесоуправления. К середине 1920-х гг. объемы лесозаготовок государственных и кооперативных организаций резко возрос- 
ли, что было связано с реализацией нэпа, оживлением внешней торговли, а также формированием новой нормативной базы функционирования лесной отрасли. Одновременно на государственном уровне было решено, что «одним из важнейших условий укрепления крестьянского хозяйства является своевременное и полное удовлетворение потребности сельского населения в древесине» [16. С. 63]. Как и в дореволюционный период, реализация этой директивы шла по нескольким направлениям. Во-первых, было принято решение о выделении из государственного лесного фонда так называемых лесов местного значения, являвшихся аналогами бывших лесных крестьянских наделов, с той разницей, что они передавались не отдельным владельцам, а коллективным хозяйствам.

В рамках провозглашенной советским правительством политики «лицом к деревне» в середине 1920-х гг. возрождается и получает свое развитие способ хозяйственной заготовки леса с последующей реализацией его населению через сеть лесных складов. Народный комиссариат земледелия РСФСР разработал целый ряд инструкций и других нормативных документов, определявших порядок отпуска лесоматериалов населению, в том числе на льготных основаниях. В 1924 1925 гг. половина всей отпускаемой из лесов РСФСР древесины предназначалась крестьянскому населению. Опыт работы лесных складов в боровых лесничествах Алтайской губернии в 1924 г. показал, что вся заготовленная древесина была реализована, что давало возможность лесной администрации увеличить объемы хозяйственных заготовок до размеров годовой лесосеки [17. С. 4 об.].
Лесосеки, отводимые для обеспечения потребностей местных крестьян, в соответствии с нормативными требованиями разделяли на две части: одна для отпуска по таксе, другая для льготных отпусков. Право на получение древесины на льготных основаниях, по определению местных органов власти, имели бывшие военнослужащие Красной армии, ведущие трудовое хозяйство, инвалиды труда и войны, безлошадные крестьяне, в том числе освобожденные от уплаты сельхозналога, нетрудоспособные граждане, члены сельскохозяйственных коммун и др.

Таким образом, система льготных и бесплатных отпусков леса являлась одним из важнейших элементов рационального лесного хозяйства на разных исторических этапах. Собственник в лице государства или отдельных ведомств брал на себя определенные обязательства по снабжению необходимой строевой или дровяной древесиной отдельных малообеспеченных категорий населения. Помимо вполне очевидной социальной направленности эта мера имела положительный эффект с точки зрения развития лесного хозяйства, снижая остроту лесного вопроса и благоприятно влияя на динамику самовольных порубок. Учитывая, что бесплатно и по льготной цене отпускался прежде всего мертвый или малоценный лес, такие отпуски приобретали характер санитарных очисток лесных дач от валежника, порубочных остатков, горелой древесины и т.п. В значительной степени принципы и способы снабжения населения древесиной зависели от государственной лесной политики, а также от конкретных социально-экономических условий и факторов.

\section{ЛИТЕРАТУРА}

1. Шевченко В.Н. Столыпинская аграрная реформа и нарастание социальной напряженности в сибирской деревне // Вестник КрасГАУ. 2014. № 6 .

2. Систематический сборник действующих циркулярных распоряжений, последовавших по Лесному департаменту МГИ с 1838 г. по 1 июля 1890 г. / составили П.Н. Вереха, И.П. Вишневский. СПб., 1890.

3. Соколов А. О мерах борьбы с лесными пожарами и самовольными порубками // Труды Съезда земельно-лесных чинов Алтайского округа в 1910 г. Барнаул, 1911

4. Тяпкин М.О. Охрана лесов Томской губернии во второй трети ХІХ - начале XX в. Барнаул, 2006.

5. Соболева Т.Н. Отношение Кабинета Е.И.В. и алтайской администрации к бедственному экономическому положению местного населения в условиях военного времени (по материалам официальной переписки 1915-1916 гг.) // Пятые научные чтения памяти Ю.С. Булыгина. Барнаул, 2009.

6. Афанасьев П.А. Кабинет его императорского величества и Алтайский округ в годы Первой мировой войны // Сибирь и войны ХІХХХ веков : сб. материалов Всерос. науч. конф. Томск, 2014.

7. Государственный архив Алтайского края (далее - ГААК). Ф. 233. Оп. 5. Д. 16.

8. ГААК. Ф. 4. ОП. 1. Д. 4677.

9. ГААК. Ф. 73. ОП. 2. Д. 10.

10. ГААК. Ф. 233. ОП. 3. Д. 12.

11. ГААК. Ф. 73. Оп. 2. Д. 25.

12. ГААК. Ф. Р-9. ОП. 1. Д. 199

13. ГААК. Ф. Р-24. ОП. 1. Д. 977.

14. ГААК. Ф. Р-150. ОП. 1. Д. 7.

15. ГААК. Ф. Р-101. Оп. 1. Д. 560

16. Колданов В.Я. Очерки истории советского лесного хозяйства. М., 1992.

17. ГААК. Ф. Р-100. Оп. 1. Д. 56.

Статья представлена научной редакцией «История» 29 августа 2016 г.

PREFERENTIAL RELEASES OF WOOD TO THE POPULATION AS PART OF THE SYSTEM OF FOREST PROTECTION IN THE SOUTH OF WESTERN SIBERIA IN THE FIRST QUARTER OF THE 20TH CENTURY

Vestnik Tomskogo gosudarstvennogo universiteta - Tomsk State University Journal, 2016, 411, 165-170.

DOI: $10.17223 / 15617793 / 411 / 22$

Mikhail O. Tyapkin, Barnaul Law Institute of the Ministry of Internal Affairs of the Russian Federation (Barnaul, Russian Federation). E-mail: tyapkin@rambler.ru 
Keywords: forest management; forest protection; privileged release of timber; forest fee; logging ticket; unauthorized felling of forest.

The article examines a component of the forest protection policy in Western Siberia. The system of preferential provision of timber for the local population was part of the state policy on the development of forestry in Siberia. This subject is quite topical and has practical importance. It allows to realize fully and evaluate the character and efficiency of state forest protection in the prerevolutionary period and in the first years of the Soviet power. This article is based on the archive documents many of which have been introduced into scientific practice for the first time. Supplying the people with wood helped to decrease the social tension in the village despite the reduction of revenues in forest exploitation; thus the amounts of free and discounted releases of wood increased during the years of the worsening of the social contradictions and mass demonstrations of peasants. After the revolutionary events of 1917 the volume of timber supplied to certain categories of the population was increased and the most favorable conditions of supply were introduced. In taiga districts, where the shortage of wood was not noticeable, the entire population, not only low income people, were entitled to get wood for free. The transfer of power to the temporary Siberian government resulted in the unification of the regulations on providing wood to the population on a preferential basis throughout the region. The right to receive free wood was granted to families of soldiers who were taken captive, missing, injured or dead, in case they were not granted a pension. The right to purchase wood at a reduced cost was granted to the refugees as well as the residents of rural areas and cities who were in need of timber for a number of reasons. After the final establishment of the Soviet power in Western Siberia in late 1919 the citizens had the right to forest management, with mandatory participation in work on protection and restoration of forests. In the mid-1920s commercial logging by state and cooperative enterprises, with the subsequent supply to the population through a network of timber depots, was developed. Former soldiers of the Red Army who kept house, disabled war veterans and workers, horseless peasants including disabled citizens who were exempted from paying agricultural tax and members of agricultural communes reserved the right to receive wood on a preferential basis. Thus, free and discounted releases of wood for the local population were one of important preventive measures which helped to decrease the topicality of the "forest issue" and prevent mass unauthorized felling of forest. In Western Siberia there was a system of preferential provision of timber for the local population, some components of it could be changed depending on the growth conditions of woods as well as on social and economic peculiarities and the political situation in the country and in the region.

\section{REFERENCES}

1. Shevchenko, V.N. (2014) The Stolypin agrarian reform and the social tension increase in the Siberian village. Vestnik Kras-GAU - Herald KrasGAU. 6. pp. 283-288. (In Russian).

2. Verekha, P.N. \& Vishnevskiy, I.P. (1890) Sistematicheskiy sbornik deystvuyushchikh tsirkulyarnykh rasporyazheniy, posledovavshikh po Lesnomu departamentu MGI s 1838 g. po 1 iyulya 1890 g. [The systematic collection of existing circular orders, followed by the Forest Department of the CIC since 1838 to July 1,1890$]$. St. Petersburg: tip. V. Bezobrazova i K.

3. Sokolov, A. (1911) O merakh bor'by s lesnymi pozharami i samovol'nymi porubkami [On measures to combat forest fires and unauthorized cuttings]. In: Trudy S"ezda zemel'no-lesnykh chinov Altayskogo okruga v $1910 \mathrm{~g}$. [Proceedings of the Congress of the land and forest officials Altai district in 1910]. Barnaul: Tipo-litogr. Gl. Upr. Alt. okruga.

4. Tyapkin, M.O. (2006) Okhrana lesov Tomskoy gubernii vo vtoroy treti XIX-nachale XXv. [Protection of forests of Tomsk Province in the second third of the 19th - early 20th centuries]. Barnaul: Azbuka.

5. Soboleva, T.N. (2009) [The attitude of HIM Cabinet and the administration of the Altai to the poor economic situation of the local population in wartime (based on official correspondence of 1915-1916)]. Pyatye nauchnye chteniya pamyati Yu.S. Bulygina [The fifth scientific readings in memory of Yu.S. Bulygin]. Barnaul: Altai State University. (In Russian).

6. Afanas'ev, P.A. (2014) [The Cabinet of His Imperial Majesty and the Altai District during the First World War]. Sibir' $i$ voyny XIX-XX vekov [Siberia and the war of the 19th-20th centuries]. Proceedings of the all-Russian conference. Novosibirsk. 8-9 June 2014. Novosibirsk: Novosibirsk State Pedagogical University.

7. State Archive of Altai Krai (GAAK). Fund 233. List 5. File 16. (In Russian).

8. State Archive of Altai Krai (GAAK). Fund 4. List 1. File 4677. (In Russian).

9. State Archive of Altai Krai (GAAK). Fund 73. List 2. File 10. (In Russian).

10. State Archive of Altai Krai (GAAK). Fund 233. List 3. File 12. (In Russian).

11. State Archive of Altai Krai (GAAK). Fund 73. List 2. File 25. (In Russian).

12. State Archive of Altai Krai (GAAK). Fund R-9. List 1. File 199. (In Russian).

13. State Archive of Altai Krai (GAAK). Fund R-24. List 1. File 977. (In Russian).

14. State Archive of Altai Krai (GAAK). Fund R-150. List 1. File 7. (In Russian).

15. State Archive of Altai Krai (GAAK). Fund R-101. List 1. File 560. (In Russian).

16. Koldanov, V.Ya. (1992) Ocherki istorii sovetskogo lesnogo khozyaystva [Essays on the History of the Soviet forestry]. Moscow: Ekologiya.

17. State Archive of Altai Krai (GAAK). Fund R-100. List 1. File 56. (In Russian). 